\title{
Caminhos de ida e caminhos de volta: temporalidade e projetos entre acadêmicos kaingang $e$ guarani na Universidade Estadual de Londrina (UEL)
}

ANA CAROLINE GOULART

\section{Introdução}

Compartilho neste artigo um pouco de minha aproximação com as experiências de 13 acadêmicos Kaingang e Guarani na Universidade Estadual de Londrina, tema a que me dediquei na dissertação de mestrado em Antropologia Social pela Universidade Federal do Paraná, concluída em 2014¹. Minha inserção formal no campo de pesquisa deu-se em abril de 2013, mas foi entre 2008 e 2009 que comecei a me aproximar dos estudantes indígenas e de suas vivências acadêmicas. Na época, atuava como bolsista pelo Programa de Formação Intercultural, coordenado pelo professor do departamento de Ciências Sociais João Valentin Wawzyniak, também membro da Comissão Universidade para os Índios (CUIA) ${ }^{2}$.

O Vestibular dos Povos Indígenas no Paraná teve sua primeira edição em 2002, após as universidades estaduais serem notificadas da Lei 13.134, publicada em 19 de abril de 2001. As instituições tiveram que organizar, de imediato, uma comissão com professores representantes de cada uma delas para a regulamentação do Vestibular, o que foi feito em parceria com a Secretaria de Estado da Ciência,

1 Os nomes de todos os meus interlocutores foram alterados na dissertação e neste artigo. As citações de entrevistas serão apresentadas no tempo passado, quando ainda eram acadêmicos, a atualização das informações será mencionada no final do artigo.

2 Embora tenha assinalado esse período como sendo de inserção formal, não houve uma marcação tão exata, pois o campo teve um caráter mais dinâmico, considerando a relação que já mantínhamos. A respeito da Comissão Universidade para os Índios (CUIA) e do Programa de Formação Intercultural, ver adiante. 
Tecnologia e Ensino Superior (SETI). Inicialmente, a Universidade Federal do Paraná não fazia parte desse processo seletivo, do qual participavam apenas as universidades estaduais. Foi em 2005, após a aprovação do Plano de Metas de Inclusão Social, que essa universidade passou a compor a política de acesso de indígenas ao ensino superior no Paraná, ofertando atualmente 10 vagas anuais, que foram aumentando progressivamente e são destinadas a indígenas de todo o território nacional (Bevilaqua 2005). Nas universidades estaduais são seis vagas em cada instituição para indígenas que comprovem - por meio de um termo de consentimento assinado pelo cacique -o seu pertencimento a uma Terra Indígena desse estado.

Começava a inclusão de indígenas no ensino superior, mas sem que as instituições pudessem ofertar a eles qualidade em seu acolhimento através de políticas de permanência. Assim, cada instituição teve que pensar em estratégias que pudessem atender a essa nova demanda, sem que houvesse um maior compartilhamento da realidade vivenciada por todas elas. $\mathrm{Na}$ Universidade Estadual de Londrina, por exemplo, foi criado em 2003 o Programa de Formação Intercultural, que tinha como principal objetivo acompanhar pedagogicamente os acadêmicos indígenas.

Conforme aumentava a presença de indígenas, aumentava também a necessidade de um diálogo maior entre as universidades para a elaboração de políticas de permanência. Nessas circunstâncias, a comissão que havia sido organizada para fins de regulamentação e elaboração do Vestibular tornou-se permanente a partir de 2005, com a denominação de Comissão Universidade para os Índios - CUIA.

Alguns critérios de permanência foram flexibilizados nas instituições estaduais para os acadêmicos indígenas, como as transferências internas e externas - que, segundo os critérios universais, não são admitidas. As segundas são possíveis nos casos em que, havendo vagas e aprovação do colegiado, o aluno pode ser transferido no segundo ano de graduação para o mesmo curso. No caso da transferência interna, também dependerá da aprovação do colegiado, com a ressalva de que poderá ser feita apenas uma vez e até o segundo bimestre do primeiro ano. Uma flexibilização que anos depois se transformou em preocupação, pois contribuía para o que as universidades passaram a denominar de "prolongamento da graduação" - quando os alunos ultrapassam o tempo considerado como "normal" (institucional).

Como essa era uma preocupação recorrente entre professores da Universidade Estadual de Londrina, tomei-a como o problema de minha pesquisa e busquei por aqueles que se encaixavam na categoria do "prolongamento". Entre eles, Kaingang e Guarani que estavam matriculados e/ou que estavam na terra indígena, na condição de "evadidos" - adiante retomarei essa categoria na perspectiva indígena. Alguns residindo em Londrina, por motivo da graduação; outros residindo na Terra Indígena, fazendo deslocamentos diários até a universidade. Esses deslocamentos eram feitos por transporte coletivo ou com automóvel próprio 3 .

Todos vinham de Terras Indígenas localizadas na região norte do Paraná, sendo as TIsKaingang: Apucaraninha, São Jerônimo e Barão de Antonina; as TIs Guarani: Laranjinha, Yvy Porã e Pinhalzinho. Isso fez total diferença para planejar o trabalho de campo, que foi por grupo focal com quem residia na

3 A falta de transporte foi considerada um problema para a maioria dos alunos, sobretudo os que saíam da T.I. Apucaraninha, a mais distante de Londrina. Os Kaingang que moravam na T.I. São Jerônimo e na T.I. Barão de Antonina utilizavam transporte próprio ou se deslocavam numa van da cidade que também levava acadêmicos não indígenas. Os Guarani que foram meus interlocutores residiam em Londrina. 
cidade, considerando a facilidade em encontrá-los; e entrevistas individuais com quem residia nas TIs, feito desse modo, pois trabalhavam nas escolas e foi difícil conciliar horários.

Neste artigo apresento um pouco da reflexão que desenvolvi em minha dissertação de mestrado acerca das experiências e temporalidades contrastivas - instituição e indígenas - e das percepções dos acadêmicos indígenas sobre permanecer na universidade e distanciar-se dela.

\section{Algumas considerações sobre o tempo institucional e o tempo indígena}

Quando se vê, já são 6 horas: há tempo...

Quando se vê, já é 6a-feira... Quando se vê, passaram 60 anos!

Agora, é tarde demais para ser reprovado... E se me dessem - um dia - uma outra oportunidade, eu nem olhava o relógio, seguia sempre em frente...

E iria jogando pelo caminho a casca dourada e inútil das horas. (Seiscentos e sessenta e seis - Mário Quintana)

"O índio gosta de fazer as coisas com calma, não dá pra fazer correndo que faz errado" (Acadêmico Kaingang)

O tempo, os desejos, as experiências. Seja em Quintana ou entre os acadêmicos Kaingang e Guarani, a temporalidade é questionada a partir de uma intencionalidade, uma intenção que sugere o novo, que proporciona vivências sem a pressão do cotidiano que, por vezes, nos coloca como sujeitos dependentes das horas, limitando as experiências, criações e sensações. Palavras ditas, mas que, em minha pesquisa de campo, pareciam não expressar muito sentido para a ordem acadêmica. Todavia, não há aqui uma perspectiva fatalista e determinista sobre as ações institucionais acadêmicas, tampouco uma essencialização da organização temporal indígena. Há somente uma inquietação acerca dos usos e concepções de tempo, de projetos e intenções para os diferentes grupos que serão abordados adiante.

É certo que o controle temporal é fundamental para a organização das instituições, um controle que é incorporado pelos agentes institucionais em suas diferentes instâncias. Em minha incursão a campo identifiquei três grupos institucionais: os técnicos administrativos, os professores (departamentos) e os professores vinculados à CUIA. As diferentes posições institucionais desses sujeitos os colocam em situações distintas com relação à política de ingresso e com os próprios acadêmicos indígenas, o que é fundamental para compreender o cenário heterogêneo ao qual me refiro.

No início do trabalho de campo - abril de 2013 - tive acesso aos técnicos responsáveis pelo controle de frequência, trancamentos e desistências dos acadêmicos indígenas. Desde o início do Vestibular são eles que, em alternância, fazem esse acompanhamento mais burocrático e representam a Pró-Reitoria de Graduação nas reuniões da CUIA. Na conversa que tive com ambos foi possível observar a burocratização das ações em cumprimento às normas que formalizam suas funções: 
Parece haver nas ações dos sujeitos um imobilismo burocratizado e burocratizante. Isto é, questões que fogem do espaço das salas com suas tabelas e computadores não podem ser analisadas portais técnicos, pois o que lhes compete é o controle de registros. Assim, os técnicos dentro das técnicas têm ainda suas relaçôes com os assuntos e sujeitos indígenas mediadas pelo papel e pela regra, ainda que no discurso e em alguns momentos esteja presente o ideal de abertura acadêmica (Goulart 2014: 88).

Em nossas conversas também demostraram a preocupação sobre os dados referentes às transferências e desistências (mesmo as não formalizadas), pois isso atrasaria ainda mais a conclusãodo curso. No entanto, a centralidade dessa preocupação esteve entre os professores, já que a relação estabelecida com os acadêmicos era em sala de aula e acompanhamento pedagógico com a oferta de monitoria ${ }^{4}$.

A cobrança do "tempo certo" foi enfática no pensamento e discurso de uma professora do curso de Educação Física, que exemplifica o que pude presenciar em momentos informais com outros professores que passaram pela CUIA. Sobre isso, registrei a seguinte fala durante uma reunião com acadêmicos indígenas de Educação Física: "Vocês estão fechando as portas da Universidade para seus filhos. O Estado vive de dados, vão ver que não tem gente se formando e vão acabar com a bolsa”. Em seguida, ao referir-se aos atrasos da leitura de textos cobrados em aula, continuou: "ninguém demora oito horas para ler um texto" (Goulart 2014:92-94).

Em outra circunstância - com entrevista gravada - disse-me:

Eu não sei se olho da lógica do capital, se olho da lógica da cultura do branco, do rendimento, de passar em todas as disciplinas, talvez eu não tenha uma paciência pedagógica para o tempo que ele precisa para se aculturar, para se adaptar. Já vivi também em outra cultura, é difícil, é diferenciado, às vezes está em outro local e não sabe o que estão falando.

Trata-se, portanto, de um tema que tomou significativas proporções, configurando a preocupação norteadora de debates entre os professores, fossem eles integrantes da CUIA ou não. A estrutura acadêmica em seus sistemas de controle que são sustentados por uma ordem burocratizada não deve ser compreendida, porém, como totalmente fechada e determinista, isto é, a universidade não é uma instituição isenta de alterações em sua ordem. Não considerar isso seria o mesmo que anular a agência dos povos indígenas e de alguns representantes institucionais que buscam essa abertura às particularidades de acadêmicos indígenas.

$\mathrm{Na}$ tentativa de compreender as experiências por trás do tempo é que busquei pelas trajetórias de alguns acadêmicos Kaingang e Guarani, pois seus trânsitos entre cursos e universidades se encaixavam no que havia sido identificado como "prolongamento da graduação". Passei a analisar o contexto de preocupação com a temporalidade a partir de duas categorias: o tempo instituído (regularmente

4 Inicialmente a ideia era conversar com professores dos cursos de Medicina e Educação Física, pois eram os dois cursos com maior presença indígena. Entretanto, foi possível entrar em contato apenas com uma professora de Educação Física - que foi indicada pelo departamento como a professora responsável por assuntos relacionados aos alunos indígenas. O colegiado de Medicina tardou a responder a solicitação que fiz, impondo, posteriormente, etapas administrativas desgastantes até chegar aos professores para entrevista, não sendo viável diante o tempo que restava. 
previsto) e o tempo vivido. Para essa reflexão me orientei pela abordagem de Evans-Pritchard em sua relação com os Nuer ao falar da inexistência de um controle temporal para a organização de suas atividades, pois partiam de uma ordem lógica dos acontecimentos. Os Nuer exerciam um controle do tempo a partir de suas necessidades e intenções e não o contrário (Evans-Pritchard 1978:116).

Entre os Kaingang e os Guarani há também outra maneira de organizar suas atividades que não essa determinada pelas horas apenas. O contraste entre o tempo instituído e o tempo vivido indica as relações extra-acadêmicas como indispensáveis para a compreensão do controle temporal. Quando o futuro acadêmico escolhe o curso ou, ainda, preenche a ficha de inscrição para o vestibular, ele não está fazendo uma escolha individual, pois toda escolha é permeada por uma expectativa coletiva, de toda a Terra Indígena. Dessa maneira, o tempo é organizado de acordo com as necessidades coletivas, de acordo com as necessidades expressas na rede de relações afetivas e de apoio que os acadêmicos indígenas firmam com família, cacique e lideranças. Essas interações serão detalhadas na terceira parte deste artigo, quando me deterei nos trânsitos indígenas que dão sentido à inconstância acadêmica ou, em termos institucionais, ao prolongamento da graduação.

Em certo momento da vida acadêmica o controle temporal despontou como uma estratégia de permanência entre os Kaingang e os Guarani, que foi observada através dos movimentos de transferências ou, por exemplo, de novos vestibulares para a mesma ou outra instituição. Porém, no início da graduação a dinâmica é outra:

"Dificuldade existe pra todo mundo, não só pra nós, mas pra você se acostumar aqui foi um fator; pra saber a rotina da cidade foi outro fator; pra saber da política dentro da universidade foi outro fator; pra saber a política dentro do curso foi outro fator. Até entender isso leva muito tempo, a gente não está acostumado com isso." (Bruno, etnia Guarani, acadêmico de Educação Física).

Há ainda que se ter domínio de novas linguagens e organização, conforme recorda o Guarani Osias Sampaio, egresso de Jornalismo:

No ensino superior há uma carga de conceitos e novas ciências que exigem um grau maior de atenção e domínio de leitura. Outra coisa é termos que nos adaptar rapidamente a memorizar endereços, códigos e senhas para tudo, agendar compromissos e aprender coisas corriqueiras (...). Essas pequenas frações se somam e interferem nos resultados acadêmicos. (Sampaio 2010:128).

Em meio a essas diferenças de todas as ordens, os acadêmicos precisavam contornar a situação para conseguir alcançar o grande sonho - a titulação de graduado. Esse caminho em busca da conclusão do curso superior por escolhas e ações objetivas, havendo em seus contornos alguns "desvios”. Isso se deveu ao encontro com a alteridade, que lhes proporcionou novos horizontes de vivências, como o lazer em bares e festas, que faz parte da rotina de qualquer estudante. $\mathrm{O}$ espaço a ser conhecido e experimentado não era apenas a universidade, era também a cidade, fato igualmente identificado por Paladino (2006) entre os Ticuna. 
Todos eles - Kaingang e Guarani - já mantinham aproximações com o espaço urbano, seja pelos deslocamentos para atendimento de saúde, no ensino fundamental e médio, seja nos acampamentos temporários para a venda de artesanatos (Tommasino 2000). O ingresso no ensino superior ampliou essa relação com o urbano, que pode ser explorado a partir de novas intenções e, por vezes, de forma solitária, já que nem todos deslocavam sua moradia para a cidade junto da família. Quanto a isso, foi essencial a afinidade entre os próprios acadêmicos para que pudessem recriar na cidade uma rede de apoio e afetos, um pouco parecida com a rede que estabeleciam com a Terra Indígena. Mesmo com essa rede de "parentes" a solidão não se dissipava, pois a cidade e universidade exigiam um grande empenho de adaptação5. (Paladino 2006; Amaral 2010; Goulart 2014).

As experiências, novas descobertas e desejos eram questionados não só por parte de alguns professores (os mais distantes da realidade indígena), mas também por parte de alunos não indígenas que contestavam o uso da bolsa-auxílio ${ }^{6}$, como lembrou a professora de Educação Física:

Aconteceu uma coisa no primeiro ano bastante desagradável. Os próprios alunos indígenas chegavam no corredor ou para os colegas de classe e começavam a contar o valor da bolsa, o que faziam com esse dinheiro. Aí teve em uma das turmas uma certa tensão, porque o valor da bolsa de quem tem filho é mais elevado e um aluno branco uma vez verbalizou: 'poxa, esses alunos indígenas não querem nada mesmo não', aí acabam sendo motivo de piada e chacota na sala de aula. Alguém tinha comprado uma moto, tinha ido em um bar, então os outros alunos ficaram dizendo: 'nosso dinheiro, nosso dinheiro, nosso imposto, eu também pago isso, também pago essa cota pra esse bando, essa corja não estudar'. Aí a gente tem que intervir.

Esse controle do gasto não é feito quando os bolsistas não possuem o recorte étnico/racial/ social. A referência a essa situação foi colocada pela professora quando demonstrava sua preocupação com o tempo que os acadêmicos indígenas permaneciam no mesmo período, repetindo por alguns anos a mesma disciplina. Um mal-estar que seria resultado do pouco empenho ou do "desleixo" por parte desses acadêmicos, conforme as próprias palavras da professora. Voltamos aqui à categoria "tempo", interpretado como desperdiçado por sujeitos que, segundo a ordem vigente, deveriam ser aqueles que tivessem mais desempenho e participação nas atividades acadêmicas.

Ainda que se fale em temporalidades distintas, o que está em jogo não é simplesmente a organização institucional pautada em cronogramas e prazos, pois o tempo quem organiza são pessoas com poder para isso. O que está para além dessas preocupações institucionais é a dificuldade estrutural em alterar modelos de acolhimento acadêmico pensando na diversidade cultural como parte da universidade e não como nomenclatura para relatórios. É preciso ressaltar que ao fazer essa afirmação não me refiro à instituição como algo abstrato, mas penso nas atitudes dos departamentos que recebem em seus cursos alunos Kaingang e Guarani, bem como dos acadêmicos não indígenas e da CUIA.

5 Utilizo o termo de adaptação por não haver um acolhimento das diferenças na cidade e na universidade, prevalecendo a ideia de que se estão nesses espaços e se assim o desejaram deverão se adaptar a eles.

6 Os valores da bolsa até o período de minha pesquisa de campo eram: R\$250 até 2003, R\$ 270 em 2004, R\$350 em 2006 e R\$ 633 em 2013. 
O antropólogo Baniwa Gersem Luciano dos Santos, em uma palestra proferida na Universidade Federal do Paraná em 2015, fez uma pertinente provocação às instituições e sujeitos que assumem uma postura de defesa de políticas inclusivas, promovendo o acesso de grupos marginalizados às estruturas educacionais sem, todavia, redefinir o pensamento institucional e as práticas ditas inclusivas. Questionou, ainda, a diferença entre inclusão e integração, já que não são raras as políticas ditas inclusivas que, na prática, não diferem dos ideais integracionistas.

Essa perspectiva da inclusão é contemplada pela fala de um de meus interlocutores, que questionou o desenrolar da política de ingresso indígena nas Universidades:

Eu não sei onde o governo que chegar, por exemplo, enfiar todo mundo dentro de uma universidade, parece que é aquela coisa, demos vagas para os índios e não souberam aproveitar. Primeiro, até entender que o cara mora em um lugar que a rotina dele é muito diferente da cidade, sair de um lugar que ele nunca saiu e morar em outro lugar, aí chega o momento em que ou você aceita viver daquela forma ou não, porque muitas pessoas desistiram por causa disso, eu regressei algumas vezes porque não conseguia me adaptar." (Bruno, etnia Guarani, acadêmico de Educação Física).

Sem muito pensar vão se delineando as contradições. Fala-se em inclusão, mas a estrutura burocrática acadêmica está "preocupada com dados", como afirmou anteriormente a professora de Educação Física. Desse modo, os acadêmicos são vistos como indivíduos que, primeiramente, devem ocultar ou mesmo anular seus desejos e experiências, pois recebem uma bolsa-auxílio. Num segundo momento, são vistos como parte de uma coletividade ${ }^{7}$, mas essa coletividade não faz parte da vida acadêmica. Isto é, não é levado em consideração o caráter coletivo dos projetos acadêmicos para preparar um (re)planejamento de ações pedagógicas ou mesmo da estrutura universitária. Como disse Roberto, Kaingang, acadêmico de Educação Física: “tinha um professor que chegava e falava ‘aqui é assim’ e falava, falava, falava e não percebia que tinha aluno indígena ali”. Essa não percepção se manifesta como proposital e também estratégica, pois quando os docentes dão visibilidade em suas aulas para os indígenas, têm que repensar seu planejamento, metodologia, recursos, avaliações. Diante disso, o mais viável é identificar todos os alunos como um só, que de preferência corresponda às suas expectativas.

\section{Caminhos cruzados - desistências, afastamentos e o caráter coletivo da formação superior.}

Temporalidades contrastivas e produtoras de um questionamento da estabilidade acadêmica através de alguns movimentos de idas e vindas da Universidade para a Terra Indígena e da Terra Indígena para a Universidade (trancamentos de matrícula, retorno à universidade e desistência). Esses movimentos são associados à ideia de inconstância acadêmica, sobretudo quando se somam aos trânsitos entre universidades que ocorrempor meio das transferências externas ou, ainda, das transferências internas.

7 Refiro-me ao mundo extra-acadêmico: família, amigos, parentes. No caso dos indígenas há ainda a presença das lideranças. 
Contudo, essa mobilidade permite observar laços e perspectivas que extrapolam o ambiente acadêmico, o que foi definido por Amaral (2010) como um "duplo pertencimento" - o pertencimento à universidade e à terra indígena. Na tentativa de fazer conviver essas duas realidades: controle científico e temporal versus controle político-social os acadêmicos Kaingang e Guarani precisam alternar suas permanências. Ora na Terra Indígena, ora na Universidade. Essa característica da bilocalidade (Sahlins 1997) é fundamental para a permanência, pois expressa a relação de troca entre quem ficou na TI e quem foi para a cidade, estabelecendo uma rede de apoio, de reciprocidade e de afetos. A bilocalidade nesse contexto está atrelada às relações de reciprocidade que vão se estabelecendo entre os que ficaram na TI e os que foram para a universidade.

A ideia de reciprocidade está presente antes mesmo do ingresso na universidade. Ela se formaliza quando há o aval do cacique através da assinatura da carta de recomendação que garante o pertencimento do candidato à Terra Indígena, pois somente mediante essa assinatura é que a inscrição no vestibular será homologada. Essa assinatura não é apenas a garantia de novas experiências educacionais e sociais, é, acima disso, um laço político que sugere algumas regras, nesse caso, o compromisso político dentro da TI durante e após a graduação. Quando Mauss descreve a sociabilidade Maori através de trocas, dádivas e reciprocidades, diz o seguinte: "esta coisa dada não é coisa inerte. Animada, amiúde individualizada, tende a regressar àquilo que Hertz chamava de seu lar de origem ou a produzir, para o clã de onde saiu, um equivalente que a substitua" (Mauss 1974: 56).

Desse modo, havia uma obrigação moral em retribuir ao cacique, lideranças e família o apoio e a confiança. A moralidade, emergindo da reciprocidade, estabelece uma necessidade de planejamento acadêmico muito particular, que deveria contemplar o retorno para a Terra Indígena, sem romper compromissos ao longo da graduação.

Sobre isso observei o esforço de acadêmicos para que as relações entre eles e a Terra Indígena não fossem abaladas, sobretudo por parte daqueles que tiveram que deslocar sua moradia para a cidade e faziam breves visitas à Terra Indígena. Por diversas vezes, as visitas durante períodos de recesso e férias se estendiam por longos dias, o que acabava prejudicando o acompanhamento do curso ou resultavam no afastamento prolongado da universidade.

Esses afastamentos não podem ser compreendidos como descompromisso. O que meus interlocutores indicavam com muita sensibilidade é que ingressar no ensino superior é reconstruir sua história e descobrir sua identidade, por inúmeras vezes passando por sofrimentos dos mais variados:

Eu sabia que eu era índia, mas eu não sabia tão profundamente o que era ser índia, vim aprender agora, depois que eu saí da aldeia, o quanto é importante e gostoso falar eu sou índia e tenho um objetivo, né, hoje eu sei porque eu estou aqui, mas antes não. Ia pra escola, no ginásio, e não tinha noção não do que era ser índio, era muito vergonhosa, chorava. (Raquel, etnia Guarani, acadêmica de Medicina). 
Lembro que nas primeiras vezes eu vinha pra UEL chorando (...). Eu lembro que quando ia pra casa a mãe fazia eu deitar no colo dela, aí eu falava 'nossa, não quero voltar pra Londrina'. Eu entrei num conflito (...). Eu volto pra Londrina com cara de funeral, eu volto pra cá como se eu estivesse presa, como se tivesse fazendo uma coisa que eu não quero. Pra eu ir pra aldeia agora, por mais que eu sinta saudade do meu filho, pra mim ir pra lá é ir pra um funeral, porque eu vejo o paraíso, mas tenho que ficar no inferno!

(Rafaela, etnia Guarani, acadêmica de Secretariado Executivo).

O sofrimento é parte de um conjunto maior de sentimentos que marcou a trajetória de meus interlocutores: sofrimento, medo, timidez, insegurança. O sofrimento aparece de forma ambígua, inicialmente como algo que fere e no meio da caminhada acadêmica transforma-se em estímulo para alcançar o sonho da conclusão. Porém, essa transformação de sentido não acontece em pouco tempo, para isso é preciso enfrentar medos: "A gente tem vontade de conversar sobre o que a gente entendeu e tirar as dúvidas, mas eu tenho medo de perguntar, de falar errado" (Marcos, etnia Kaingang, acadêmico de História). Foi preciso também refazer os caminhos.

Sentimento muito presente entre os acadêmicos indígenas, o medo é resultante de uma série de experiências passadas com os não índios que, de alguma forma, inferiorizaram a identidade, história e cultura indígenas. Wawzyniak (2010) utiliza o conceito de "trauma cosmológico" de Rouanet (2004:12 apud Wawzyniak 2010:56) para explicar o efeito do contexto de violência pelo qual passaram os povos indígenas.

Em nossos encontros, no grupo focal, esse foi um tema muito associado ao período escolar. Nesses momentos me deparei com lembranças da violência simbólica, ideológica e física que sofriam na escola. Uma infância marcada pelo que D’Angelis (2008) denominou “alienação da própria história”, isto é, saberes que inferiorizavam e ocultavam a história indígena: "Na minha época não tinha professor indígena, minha professora do primário era muito rígida, daquela que batia nos alunos. [Na escola] o que eu aprendi mesmo é que o índio é um estorvo" (Raquel, etnia Guarani, acadêmica de Medicina).

Quando os estudos tinham que ser continuados na cidade, os constrangimentos aumentavam, como rememorou Marcela, da etnia Kaingang, acadêmica de Serviço Social: "eu lembro que a gente tinha um grupo de dança e a gente ia se apresentar lá na escola que eu estudava, eu tava na $8^{a}$ série. Nossa, todo mundo vaiou, eu fiquei super mal, com vergonha, não queria mais voltar pra escola, aí, por isso, a gente se reprime".

Essas marcas adquiridas na infância e revividas cotidianamente na relação com os não índios faz com que cheguem ao ensino superior receosos e sem saber ao certo como lidar com essas novas informações que precisam processar rapidamente. $\mathrm{O}$ interessante a ser mencionado é que, entre os acadêmicos Kaingang, a maioria atuava como professor nos anos iniciais nas escolas em suas aldeias ${ }^{8}$. $\mathrm{O}$ trabalho desenvolvido na escola por esses profissionais-acadêmicos é de excelente qualidade e o fazem com muita segurança. Quando o ambiente é a sala da universidade e a posição deles é a de alunos, o protagonismo desaparece, o comportamento se altera e passam a incorporar a insegurança, a timidez e 
o medo. Wawzyniak (2009) e Amaral (2010) se debruçaram sobre esses três aspectos da vida acadêmica destacando a relação comas situações de preconceito que envolve linguagem, comunicação, marcas estéticas e mesmo pela particularidade do processo seletivo, considerado por alguns como privilégio. A reflexão sobre esses sentimentos também aparece na fala de Mariana, Kaingang, acadêmica evadida de Pedagogia:

“Tem uns que têm vergonha de dizer que é indígena, teve uma no ano passado que disse ser japonesa. Antes existia aquela coisa de que o não índio é muito inteligente, tem uns mais velhos que ainda falam isso: 'ah, o índio é burro, o branco é que é inteligente'. Eles não conseguiam entender essa diferença, né(...). O medo é sim muito presente. Acho que é insegurança, você é diferente lá dentro (...). Você sabe que desde 1500 o índio vem sendo massacrado como burro, a cultura é diabólica, agora, de uns 30 anos pra cá: 'não, você tem que mudar, tem que estudar, sua cultura é importante', então acho que ele não consegue identificar quem ele é. Então, você é índio ou não?

Dialogando com a ideia de trauma cosmológico, a reflexão de Novaes sobre auto-imagem foi fundamental para compreender as referências indígenas sobre si e sobre o outro. Conforme a autora, a auto-imagem consiste de percepções alteradas de acordo com o contexto e a situação vivenciada, constituindo uma variação de imagens positivas e negativas sobre si:

"A auto-imagem de um grupo ou sociedade pode ser analisada a partir de um recurso metafórico: o jogo de espelhos. Quando uma sociedade focaliza outro segmento populacional, ela simultaneamente constitui uma imagem de si própria, a partir da forma como se percebe aos olhos deste outro segmento. É como se o olhar transformasse o outro em um espelho (...) cada outro, cada segmento populacional, é um espelho diferente, que reflete imagens diferentes entre si” (Novaes 1993:107).

Voltar para a Terra Indígena era o caminho encontrado para manterem-se seguros e acolhidos, mas acabavam retornando à universidade em algum momento. Uma perspectiva parecida era a dos que, no meu período de campo, estavam afastados da universidade.

Foi a partir dessas experiências que pude compreender que algumas categorias são insustentáveis quando pensadas em relação à complexidade dos projetos indígenas. Nesse caso, foi preciso rever o uso que se dá ao termo desistência - caracterizado como um afastamento prolongado.

Revendo as análises que fiz na dissertação sistematizei nessa nova leitura do tema duas formas de se pensar esses afastamentos da Universidade que, em termos institucionais, são denominados "trancamento" e "desistência". Assim, destaco as seguintes variações da permanência: a permanência institucionalizada- quando há um vínculo por matrícula e frequência - e a permanência liminar, quando o vínculo é simbólico e real (ainda que não seja institucional), isto é, não são acadêmicos, mas também não são desistentes.

Tanto aqueles que estavam matriculados no período de pesquisa quanto os que haviam retornado para a Terra Indígena faziam menções aos afastamentos temporários como diretamente associados ao prolongamento, mas não somente como são associados pela universidade: desistências e trancamen- 
tos que prejudicam o desempenho e finalização do curso. Ao contrário disso, a associação feita pelos próprios acadêmicos era no sentido de que esses afastamentos eram necessários para que futuramente apresentassem um bom desempenho e concluíssem o curso. Essas divergências nas significações do prolongamento revelam a dualidade do termo.

Essa dualidade aparece na percepção da acadêmica Guarani Raquel, que há 15 anos persiste em cursar Medicina:

"Você pensa que eu não fiquei angustiada de ter feito outros vestibulares, de ter dado essa estacionada? Eu fico angustiada com isso, já era pra eu ter terminado, já era pra estar na aldeia ajudando, mas Deus sabe de tudo, passei por coisas, assim, que só Deus (...). Esse tempo não foi à toa, estou aprendendo mais, aprendendo a entender as pessoas, a me entender, né, porque até um tempo atrás eu não me entendia (...). O índio tem dificuldade de acompanhar mesmo, aí tem índio que se afasta, reprova por falta, aí é onde a universidade não está preparada nisso, pra dar esse apoio, não adianta forçar que a gente não vai conseguir, nós temos o nosso tempo e a universidade não entende isso. Aqui a gente tem esse problema, na UEM também, nas outras universidades também, aí você não sabe porque o índio voltou embora pra aldeia correndo”.

Se, por um lado, Raquel se angustia com o tempo que está na universidade, por outro se tranquiliza, reconhecendo que esse tempo não foi desperdiçado, mas aproveitado para se reconhecer, para refazer sua história e cuidar de suas feridas. Sendo assim, não é possível limitar a compreensão do prolongamento como algo somente bom ou somente ruim, há nas entrelinhas histórias, identidades, dores e expectativas que dão um sentido muito singular a essa temporalidade acadêmica nos percursos indígenas.

Quanto mais se prolonga, mais o sonho é adiado. Quanto mais se prolonga, mais experiências são vivenciadas. Quanto mais se prolonga, mais aumenta o sofrimento. Quanto mais se prolonga, mais se conhece os próprios limites. Nessas circunstâncias, a retribuição da dádiva foi adiada, entrando num estado de suspensão, mas não de rompimento. Todavia, caso se explicite a recusa em fazer a retribuição, abre-se espaço para diversos conflitos, pois foi confirmado o rompimento dos laços políticos, que geram uma dívida não apenas com o cacique, mas com todos os moradores da TI. Ou seja, aqueles que se formam e não retornam para a TI a fim de contribuir com seus novos conhecimentos irão manter uma dívida e sua postura será interpretada como a de alguém que "virou branco".

Para os que estavam vivenciando o retorno à T.I. sem ter concluído o curso, a dádiva suspensa seria tão logo retribuída à "comunidade", mas antes precisavam aproveitar o tempo de afastamento parase refazer e assimilar as experiências anteriores. No estágio da liminaridade - não desistente e não acadêmico - é possível perceber os efeitos da vida acadêmica no cotidiano das aldeias. Todos contam com esse "não desistente" que, por sua vez, entra num processo de estranhamento de si próprio para aí então refletir de outra maneira sobre as experiências, traçando estratégias possíveis de transformação não só do social/coletivo, mas também de si. É preciso ainda perceber que esse estágio liminar envolve

9 Dois Kaingang, da TI Apucaraninha, é que assumiram não ter intenção de retornar à universidade. 
uma nova reflexão sobre a formação acadêmica, as consequentes responsabilidades e a própria identidade étnica.

Embora as perspectivas de afastamentos temporários sejam semelhantes, há diferentes maneiras de se viver esse momento liminar entre os Kaingang e os Guarani. Os Kaingang que foram meus interlocutores tinham um vínculo de trabalho dentro da TI, em sua maioria, como professores. Havia, portanto, entre os demais, uma confiança e uma grande expectativa pela conclusão do curso. Na mesma medida, havia a cobrança, sobretudo por parte do cacique e lideranças, como enfatizam dois Kaingang da T.I. Apucaraninha:

“No início até falei pra minha mãe: 'eu vou largar do meu trabalho, acho que só vou estudar'. Aí
ela disse assim” 'você pensa bem, porque você tem seus filhos, como você vai criar?' Aí já fica meio
assim, daí a própria liderança falou assim pra mim: 'se você for estudar, quem vai ficar na escola?
Você sabe que você ajuda muito na escola. Se você sair, como que vai ficar essa escola?’” (Mariana,
acadêmica evadida de Pedagogia).

Eu penso também nos meus alunos, porque se eu sair de lá ninguém vai me substituir. Quando o diretor sai eu fico como diretor também. Quando tem alguma coisa pra buscar aqui [na Sede] eu que venho, quando é pra levar alguma coisa lá pro Barreiro [outra divisão nos limites de Apucaraninha] eu que vou levar. (...) Precisa sim de outro professor, mas não tem ninguém, ninguém quer ir" (Marcos, acadêmico de Educação Física).

Por ocuparem esse espaço de destaque - que os faz usufruir de certo status - e por afastarem-se da Universidade para não descumprirem seus compromissos na aldeia, os demais moradores da TI não os cobram com tanto apelo, desde que os afastamentos não sejam recorrentes.

No caso dos Guarani, as atividades dentro da TI foram oportunizadas após o ingresso na Universidade, até mesmo por serem mais jovens que os Kaingang em questão. Esse afastamento proporcionava reflexões e experiências influenciadas pelo período em que estiveram na universidade e influenciadoras de novas tomadas de decisão.

O Guarani Miguel, da TI Yvy Porã, afirmou ser o seu melhor momento - aquele de retorno à TI -, já que havia começado a trabalhar na escola e teria descoberto o que realmente lhe dava prazer. Envolvido com a política da aldeia e com a escola sentiu-se mais motivado para continuar a graduação, desde que não precise mudar para a cidade novamente, lembrando que esse período lhe desencadeou um início de depressão.

Para a Guarani Fernanda, um ano afastada, esse tempo seria necessário para recompor suas energias: "vou ficar um ano descansando. Eu já estava cansada mesmo. Ano que vem vou fazer de novo! Eu vim embora antes de ficar doente. Ele [Miguel] estava entrando em depressão já, aí falamos pra ele voltar, o pai dele já arrumou trabalho pra ele também”.

Um dos questionamentos dos técnicos que fazem o controle de matrícula e frequência é que grande parte daqueles que retornavam para a TI não formalizavam o trancamento. Pelos relatos de meus interlocutores é possível presumir que essa não formalização diga respeito à liminaridade, isto 
é, a matrícula não foi trancada porque o tempo a permanecer afastado seria de curta duração - mas acabavam perdendo o semestre/ano ou ficavam retidos em muitas disciplinas.

A variação do sentido da permanência e a inconstância acadêmica são compreendidas em minha dissertação como implicação e, ao mesmo tempo, implicadoras de um processo reflexivo e transformador. Essa transformação não é individual somente, é também a partir dessa inconstância que a atenção institucional volta-se aos acadêmicos e a estrutura universidade passa por uma reavaliação, tema que incluo nessa reflexão na última parte do artigo.

Como mencionei anteriormente, foi preciso se comprometer a enfrentar medos e sofrimentos, refazendo caminhos como agentes transformados e transformadores.

\section{Período pós-dissertação: entre os sujeitos e a instituição}

Quatro anos após o período formal de trabalho de campo, novas experiências foram traçadas por meus interlocutores e pelos agentes institucionais, sobretudo os que integram a CUIA. Portanto, vejo como pertinente uma revisão de informações. Nesse caso, duas situações merecem destaque, a primeira é o avanço no debate e proposição de ações para a permanência; a segunda é a situação acadêmica em que se encontram aqueles que foram meus interlocutores.

Anteriormente me referi à reflexão compartilhada por Gersem Baniwa acerca de políticas inclusivas como práticas integracionistas, volto a ele para pensar nas mudanças ocorridas durante esse período. O objetivo aqui é pensar como o prolongamento da graduação provocou os agentes institucionais (CUIA) e os impulsionou a se apropriar politicamente disso para alterar a estrutura acadêmica.

Agentes institucionais (CUIA) e acadêmicos indígenas se apropriaram dos códigos e da lógica interna de organização para alterar a estrutura acadêmica. Os dados deixam de ser números ou problemas e transformam-se em recursos legitimadores para a transformação da estrutura. Quando a professora de Educação Física diz que o estado vive de números e com o atraso os acadêmicos indígenas estariam fechando a porta da universidade para seus filhos, impõe-se uma perspectiva negativa sobre essa permanência instável. Entretanto, pode-se utilizar esses trânsitos e esse outro uso do tempo para rever a estrutura institucional, partindo agora da perspectiva indígena e não da perspectiva da instituição (todos devem se adaptar). Sendo altos os índices de "evasão" e "repetência" - que contribuem para o prolongamento -, então a estrutura deve ser alterada. Se, por um lado, há uma preocupação com dados, por outro lado há uma reação a essa rigidez.

Desde minha atuação como monitora e, posteriormente, como pesquisadora, pude presenciar certas concepções sobre a formação superior indígena um tanto fechadas, sem espaço para a tentativa de horizontalização de diálogo (Cardoso de Oliveira 2000) que pudesse alterar a estrutura acadêmica para que acolhesse a pluralidade de saberes. Os "interesses institucionais" não podem ser vistos de modo homogêneo, pois se destaca algum movimento mais crítico em relação à organização acadêmica. Ressalta-se, dessa maneira, que esse processo de descolonização também tem em suas bases uma presença institucional, ainda que de modo reduzido, mas que contribui com práticas que caminham no sentido de alguma transformação da estrutura universitária. 
As ações mais próximas disso eram tomadas pela CUIA, como no caso da transferência interna, que na época destacou-se como uma flexibilização acadêmica que reduziria os índices de evasão, já que havia sido identificado que um dos fatores de "desistência" estaria relacionado ao pouco ou nenhum conhecimento sobre o curso escolhido e por enfrentarem dificuldades em interpretação e produção de textos, por exemplo. Contudo, essa flexibilização abriu brechas para a instabilidade que resultava no prolongamento da graduação. A fim de amenizar essa instabilidade e oferecer ao acadêmico uma base mais consistente sobre a vida universitária (códigos, normas, prazos, conhecimentos básicos), a CUIA deu início ao Ciclo de Iniciação Acadêmica.

Criado em novembro de 2013 e aprovado em novembro de 2014 pelo Conselho de Ensino Pesquisa e Extensão e pelo Conselho Administrativo da UEL, o projeto do Ciclo foi sistematizado entre a CUIA e a PROGRAD a partir do levantamento de dados acerca da evasão indígena entre os anos de 2002 a 2013 (Alves 2016).

Conforme consta na Resolução CEPE/CA nº133/2013, também mencionada em minha pesquisa, a organização curricular do Ciclo foi dividida em quatro eixos temáticos: 1. Terra e identidade; 2. Ciência e Saúde; 3. Cidadania e Sustentabilidade; 4. Cotidiano Acadêmico. Não foi possível acompanhar o início das atividades do Ciclo quando finalizava a dissertação mas, em 2016, Roseli Alves defendeu sua dissertação - na área de Políticas Públicas, na Universidade Estadual de Maringá - que trata especificamente da estruturação e aplicação desse projeto. Sua pesquisa apresenta uma análise documental e de entrevistas com integrantes da CUIA, professores do Ciclo e acadêmicos indígenas que passavam por essa nova experiência que, no momento, acontece apenas na UEL.

Todos os alunos que tenham optado pela UEL deverão passar obrigatoriamente pelo Ciclo durante 12 meses, apenas após o parecer positivo dos professores é que os alunos poderão se matricular em algum curso de sua preferência. Essa estratégia de ação na estrutura legitima o prolongamento da graduação - reaparece aqui o caráter dual do termo/situação.

Visto primeiramente como prejudicial, o prolongamento toma nova forma, também por parte dos professores da CUIA, que a oficializam através de uma alteração na permanência, a fim de reduzir os índices de evasão, trancamento, "desistência", pois através dessa iniciação os acadêmicos estariam mais familiarizados com a ordem universitária.

A criação do Ciclo proporcionou, segundo Alves (2016) significativas mudanças na forma como os acadêmicos indígenas interagem com as normas, códigos acadêmicos e nas relações sociais:

“[o ciclo] já apresenta possibilidades de ações formativas significativas que podem avançar na construção de uma identidade interdisciplinar e intercultural junto aos estudantes indígenas da UEL, contribuindo para uma maior visibilidade e para o enfrentamento das situações de todo tipo de dificuldade, além de um desempenho mais satisfatório no curso que realizam" (ALVES 2016:103).

Esse novo cenário que vai despontando na UEL é reflexo da mudança de olhar dos agentes institucionais (CUIA), que do ingresso voltou-se à permanência. A partir do momento em que essa mu- 
dança começou a acontecer - entre 2012 e 2013 -, transformações mais estruturais passaram a se consolidar, ampliando as possibilidades de se vivenciar a universidade.

Entretanto, Alves (2016) ainda destaca os problemas enfrentados nesse período de consolidação do Ciclo, problematizando, por exemplo, a rotatividade da CUIA-UEL - fato que também mencionei na dissertação.

A rotatividade de professores diz muito sobre a familiarização ou não que possuem com as temáticas indígenas. Todos os anos os departamentos eram convocados, por meio de documento expedido pela PROGRAD, a elegerem um professor representante dos alunos indígenas que deveria compor a CUIA. Todavia, em 2011 começava um movimento diferente na convocação dos professores, não dependendo apenas da formalidade do documento enviado aos departamentos, pois os professores que já integravam a Comissão faziam o convite pessoalmente, possibilitando um diálogo mais próximo com os departamentos. Esse movimento parece ter resultado numa equipe com um perfil mais afinado com as demandas que surgem nesse plano de ingresso de indígenas no ensino superior.

Em minha pesquisa fiz um levantamento das áreas de interesse de pesquisa dos professores da CUIA e, dos treze integrantes, apenas cinco se aproximavam de temas que poderiam proporcionar uma relação mais dialógica (Cardoso de Oliveira 2000). Revendo a composição da CUIA-UEL, dos treze professores atuais, apenas uma não possui pesquisas e projetos com temáticas que dialoguem com os povos indígenas; os outrosdoze professores possuem produções e intervenções que tratam diretamente da temática indígenas ou tratam de temas que perpassam os direitos humanos, crítica à educação para o capital, saúde comunitária etc.

As mudanças não se deram apenas entre os setores institucionais, mas também na trajetória de meus interlocutores Kaingang e Guarani. Para sistematizar essas mudanças, atualizei uma tabela que elaborei para a dissertação. O campo "situação acadêmica" foi inserido para este artigo. É possível observar um pouco do percurso dos meus interlocutores que na época da pesquisa estavam matriculados e os que estavam na TI numa fase de liminaridade - esses são identificados na tabela com um asterisco:

Tabela 1: Atualização das informações sobre os interlocutores - maio 2017

\begin{tabular}{|c|c|c|c|c|c|c|c|}
\hline Cursos & Etnia & $\begin{array}{c}\text { Data do } 1^{\circ} \\
\text { ingresso }\end{array}$ & $\begin{array}{c}\text { Ano fre- } \\
\text { quentado }\end{array}$ & $\begin{array}{c}\text { Duração do } \\
\text { curso }\end{array}$ & $\begin{array}{c}\text { Transferên- } \\
\text { cia Interna }\end{array}$ & $\begin{array}{c}\text { Transferên- } \\
\text { cia Externa }\end{array}$ & $\begin{array}{c}\text { Situação } \\
\text { acadêmica }\end{array}$ \\
\hline Medicina & Guarani & 2002 & - & 6 anos & Não & Sim & Internato \\
\hline Pedagogia* & Kaingang & 2003 & $2^{\circ}$ ano & 4 anos & Sim & Não & $\begin{array}{c}\text { Matriculada } \\
\text { em Peda- } \\
\text { gogia ead } \\
\text { UEM. }\end{array}$ \\
\hline Artes Visuais* & Kaingang & 2004 & - & - & Sim & Não & Afastado \\
\hline $\begin{array}{c}\text { Educação } \\
\text { Física }\end{array}$ & Guarani & 2005 & - & - & Não & Não & $\begin{array}{c}\text { Formado } \\
\text { em } 2014\end{array}$ \\
\hline $\begin{array}{c}\text { Secretariado } \\
\text { Executivo }\end{array}$ & Guarani & 2005 & - & - & Sim & Não & $\begin{array}{c}\text { Formada } \\
\text { em } 2013\end{array}$ \\
\hline $\begin{array}{c}\text { Serviço Social } \\
\text { Kaingang }\end{array}$ & 2006 & - & Sim & Não & $\begin{array}{c}\text { Formada } \\
\text { em } 2015\end{array}$ \\
\hline
\end{tabular}


Tabela 1: Atualização das informações sobre os interlocutores - maio 2017

\begin{tabular}{|c|c|c|c|c|c|c|c|}
\hline Cursos & Etnia & $\begin{array}{c}\text { Data do } 1^{\circ} \\
\text { ingresso }\end{array}$ & $\begin{array}{l}\text { Ano fre- } \\
\text { quentado }\end{array}$ & $\begin{array}{c}\text { Duração do } \\
\text { curso }\end{array}$ & $\begin{array}{l}\text { Transferên- } \\
\text { cia Interna }\end{array}$ & $\begin{array}{l}\text { Transferên- } \\
\text { cia Externa }\end{array}$ & $\begin{array}{c}\text { Situação } \\
\text { acadêmica }\end{array}$ \\
\hline $\begin{array}{l}\text { Educação } \\
\text { Física }\end{array}$ & Kaingang & 2009 & $\begin{array}{l}\text { Não in- } \\
\text { formado }\end{array}$ & - & - & - & $\begin{array}{c}\text { Matriculado } \\
\text { em Educa- } \\
\text { ção Física } \\
\text { na UEM }\end{array}$ \\
\hline Odontologia & Guarani & 2007 & - & 5 anos & Sim & Sim & $\begin{array}{l}\text { Optou por } \\
\text { não retornar }\end{array}$ \\
\hline $\begin{array}{l}\text { História* (in- } \\
\text { cluído nessa } \\
\text { tabela) }\end{array}$ & Kaingang & & $\begin{array}{l}\text { Não in- } \\
\text { formado }\end{array}$ & & & & Matriculado \\
\hline $\begin{array}{l}\text { Ciências } \\
\text { Sociais* (in- } \\
\text { cluída nessa } \\
\text { tabela) }\end{array}$ & Guarani & 2006 & $\begin{array}{l}\text { Não in- } \\
\text { formado }\end{array}$ & 4 anos & Sim & & Matriculada \\
\hline $\begin{array}{l}\text { Direito*(in- } \\
\text { cluído nessa } \\
\text { tabela) }\end{array}$ & Guarani & 2008 & $\begin{array}{l}\text { Não in- } \\
\text { formado }\end{array}$ & 5 anos & Sim & Não & $\begin{array}{l}\text { Universida- } \\
\text { de de Ponta } \\
\text { Grossa. }\end{array}$ \\
\hline
\end{tabular}

Fonte: A Autora.

Há ainda aqueles interlocutores que se formaram e tentaram ingressar no mercado de trabalho, conforme indico a seguir:

Tabela 2: Interlocutores egressos - maio 2017.

\begin{tabular}{|c|c|c|c|}
\hline Etnia & $\begin{array}{c}\text { Tempo de experiência } \\
\text { acadêmica }\end{array}$ & Área de formação & Atuação profissional \\
\hline Kaingang & $2006-2015$ & Serviço Social & $\begin{array}{c}\text { Bolsista recém-formada em projeto de exten- } \\
\text { são na área de educação indígena }\end{array}$ \\
\hline Guarani & $2005-2014$ & Educação Física & Educador Social \\
\hline Guarani & $2005-2013$ & Secretariado Executivo & $\begin{array}{c}\text { Trabalhou como secretária na Articulação dos } \\
\text { Povos Indígenas do Sul por um ano. }\end{array}$ \\
\hline
\end{tabular}

Fonte: A Autora.

Nesse período de quatro anos outros trânsitos entre cursos e universidades foram feitos, conclusões foram alcançadas e novos rumos foram tomados no exercício ou não de suas profissões, alguns planejando o ingresso no mestrado, outros em especializações. Por fim, a mobilidade permanece, outras experiências/expectativas e novas alterações institucionais vão transformando o cenário da universidade e das Terras Indígenas. 


\section{Consideraçóes finais}

Explico agora o título do artigo, inspirado na referência feita por Manuela Carneiro da Cunha, em seu livro Cultura com Aspas. A autora inicia o texto fazendo menção aos gêneros musicais do flamenco da Espanha - cantes de ida y vuelta -, que foram apropriados e transformados nas colônias: "Daí serem conhecidos como cantos de ida e volta". Essa relação é feita para se chegar ao conceito de "cultura" dizendo que "os povos da periferia foram levados a adotá-la (...) desde então, a "cultura" passou a ser adotada e renovada na periferia. E tornou-se um argumento central" (Carneiro da Cunha 2009:312). $\mathrm{O}$ mesmo pode ser pensado com os acadêmicos indígenas, pois ir e voltar é a cada vez diferente. Vai-se de um jeito e volta-se de outro; tanto a volta para a TI quanto a volta para a universidade carregam significações distintas.

Ao destacar o "caminho de ida e caminho de volta" propus pensar na relação estreita entre Terra Indígena, Cidade e Universidade. Considerando, a partir disso, que há nas relações entre esses três espaços uma complexidade de sentimentos e vivências que não devem ser compreendidos como movimentos irresponsáveis. O que o trabalho de campo - e as afinidades que o precederam - me indicavam é o exato oposto disso, tanto para os que na época estavam matriculados, quanto para os que estavam temporariamente afastados.

Os principais fatores que envolvem os afastamentos da Universidade são: domínio dos códigos acadêmicos, convivência (solitária) com a cidade, coletividade de projetos, descolonização histórica e identitária. Não é possível vivenciar esses processos de (re)conhecimentos conforme a lógica e os interesses institucionais apenas. Portanto, ir e voltar denota um deslocamento em ebulição, repleto de angústias e que pode ser compreendido num sentido oswaldiano de antropofagia cultural, já que há um enfrentamento e uma deglutição do que se deseja como seu. Assim, o objetivo é assimilar o outro (alteridade) e não se integrar a ele através da "inclusão". Há diante disso uma tentativa de descolonização estrutural que tem sido proposta a partir da não adaptação do sujeito à estrutura. A agência indígena toma espaço, a agência de sujeitos institucionais toma espaço. Nenhuma situação de dominação deve ser vista como acima do poder de (re)ação dos sujeitos; como afirma Ortner (2007), há uma "instabilidade do poder". O que esses percursos de "prolongamento" demonstram é que se faz necessária a compreensão dos processos particulares de familiarização e subversão de ordens e interesses, buscando pelos sentidos que os acadêmicos atribuem às suas trajetórias.

Ana Caroline Goulart é graduada em Ciências Sociais pela UEL e mestre em Antropologia pelo PPGA/UFPR. 


\section{REFERÊNCIAS BIBLIOGRÁFICAS}

ALVES, Roseli. 2016. O Ciclo intercultural de iniciação acadêmica para estudantes indígenas da Universidade Estadual de Londrina. Dissertação (Mestrado em Políticas Públicas). Maringá: Universidade Estadual de Maringá.

AMARAL, Wagner Roberto. 2010. As trajetórias dos estudantes indígenas nas universidades estaduais do Paraná: sujeitos e pertencimentos. Tese (Doutorado em Educação). Curitiba: Universidade Federal do Paraná.

BEVILAQUA Ciméa Barbato. 2005. "Entre o previsível e o contingente: etnografia do processo de decisão sobre uma política de ação afirmativa”. Revista de Antropologia 48(1):167-225.

CARDOSO DE OLIVEIRA, Roberto. 2000. O trabalho do antropólogo. 2. ed. Brasília: Paralelo 15; São Paulo: Editora UNESP.

CARNEIRO DA CUNHA. Manuela. 2009. “Cultura” e cultura: conhecimentos tradicionais e direitos intelectuais". In Cultura com aspas. São Paulo: Cosac Naify.

D’ANGELIS, Wilmar da Rocha. 2008. "Educação escolar e ameaça à sobrevivência das línguas indígenas no Brasil Meridional”. BRASA IX - New Orleans/LO, USA, 27-29 mar.

EVANS-PRITCHARD, E. E. 1978. Os Nuer. São Paulo: Perspectiva.

GOULART, Ana Caroline. 2014. Experimentar, contestar e refazer-se: caminhos de sonhos e enfrentamentos percorridos por acadêmicos Kaingang e Guarani na Universidade Estadual de Londrina - PR. Dissertação (Mestrado em Antropologia Social). Curitiba: Universidade Federal do Paraná.

MAUSS, Marcel. 2003. “Ensaio sobre a dádiva: forma e razão da troca nas sociedades arcaicas”. In Sociologia e Antropologia. São Paulo: Cosac Naify.

NOVAES, Sylvia Caiuby. 1993. Jogo de espelhos. São Paulo: EDUSP.

ORTNER, Sherry. 2007. "Poder e Projetos: reflexões sobre a agência”. In Miriam Pillar Grossi; Cornelia Eckert; Peter Fry (orgs.). Conferências e diálogos. Saberes e práticas antropológicas. Brasília: ABA; Blumenau: Nova Letra.

PALADINO, Mariana. 2006. Estudar e Experimentar a cidade: Trajetórias sociais, escolarização e experiência urbana entre "Jovens" indígenas ticuna, Amazonas. Tese (Doutorado em Antropologia Social). Rio de Janeiro: Universidade Federal do Rio de Janeiro.

SAHLINS, Marshall.2011. "O pessimismo sentimental e a experiência etnográfica: por que a cultura não é um “objeto” em via de extinção”, parte II. Mana3(2): 103-150.

SAMPAIO, Osias Ramos Arnaud. 2010. A universidade como área de influência: o olhar de um Guarani sobre sua trajetória acadêmica. In Maria Simone Jacomini Novak et al. Educação Superior 
Indigena no Paraná. Maringá: EDUEM.

WAWZYNIAK, João Valentin. 2010. "Esboço de uma reflexão sobre a presença de índios no ensino superior no Paraná”. In Maria Simone Jacomini Novak et al. Educação Superior Indígena no Paraná. Maringá: EDUEM. 


\title{
CAMINHOS DE IDA E CAMINHOS DE VOLTA: TEMPORALIDADE E PROJETOS ENTRE ACADÊMICOS KAINGANG E GUARANI NA UNIVERSIDADE ESTADUAL DE LONDRINA (UEL)
}

Resumo: Acompanhar o percurso dos acadêmicos indígenas na Universidade não pode ser compreendido como algo linear. Ao contrário, trata-se de um percurso marcado por curvas que, aos poucos, vão indicando diferentes modos de se relacionar com a instituição e seus agentes, com a vida acadêmica e política, com seus desejos profissionais e, ainda, com a própria história e identidade.Permanecer na Universidade e construir o projeto de formação superior não cabe apenas ao acadêmico, mas também a sua rede familiar e lideranças. Essa rede de relações e o reencontro consigo mesmo são alguns dos fatores diretamente associados ao tempo de permanência na graduação, uma temporalidade que é caracterizada pelo afastamento temporário da universidade e pelos trânsitos entre instituições e cursos. Diante disso, procurei compreender essas curvas, trânsitos e significações sobre ser um acadêmico Kaingang e Guarani no norte do estado do Paraná.

Palavras-chave: Universidade; permanência; Kaingang e Guarani; temporalidade; Paraná

\section{WAY TO AND WAY BACK: TEMPORALITY AND PROJECTS BETWEEN KAINGANG AND GUARANI ACADEMICS AT THE STATE UNIVERSITY OF LONDRINA}

\begin{abstract}
The academic career of indigenous university students should not be taken as linear. Contrariwise, it is a winding path that gradually indicates different ways of relating to the institution and its agents, academic and political life, professional goals, and to their own history and identity. Staying in the University and building a higher education project does not concern the student alone, but also involves his/her kindred and indigenous leaders. This network of relations, as well as the re-encounter with himself/herself, impact directly on the length of time necessary to complete undergraduate education - a time characterized by temporary absences from the university and by academic drifts involving institutions and courses. Regarding this, I tried to understand these paths and drifts, and what it means to be a Kaingang and Guarani university student in the North of the state of Paraná, Brazil.
\end{abstract} Keywords: University, permanence, Kaingang and Guarani, temporality, Paraná.

RECEBIDO: $31 / 05 / 2017$

APROVADO: 09/11/2017 